\title{
Transcriptional Regulation of Glial Fibrillary Acidic Protein by Corticosterone in Rat Astrocytes in Vitro Is Influenced by the Duration of Time in Culture and by Astrocyte-Neuron Interactions*
}

\author{
IRINA ROZOVSKY, NICHOLAS J. LAPING, KNUT KROHN, BRUCE TETER, \\ JAMES P. O'CALLAGHAN, AND CALEB E. FINCH \\ Andrus Gerontology Center and Department of Biological Sciences, University of Southern California \\ (I.R., C.E.F., B.T., K.K.), Los Angeles, California 90089-0191; the Renal Pharmacology Department, \\ SmithKline Beecham Pharmaceuticals (N.J.L.), King of Prussia, Pennsylvania 19406; and the \\ Neurotoxicology Division, United States Environmental Protection Agency (J.P.O.), Research Triangle \\ Park, North Carolina 27711
}

\begin{abstract}
In the rat hippocampus and cortex, the transcription of glial fibrillary acidic protein (GFAP), an astrocyte intermediate filament protein, is inhibited by glucocorticoids. The present study examined the regulation of GFAP expression by glucocorticoids in astrocytes in vitro. Corticosterone (CORT) increased GFAP messenger RNA, protein, and transcription rates in cultured primary neonatal astrocytes, responses opposite the GFAP responses to CORT in vivo. The direction of GFAP regulation by corticosterone in vitro is reversed by coculture with neurons or by extended culture for 3 months. The switch in the direction of GFAP regulation by CORT during prolonged
\end{abstract}

culture is associated with a 3 -fold increased prevalence of type II glucocorticoid receptor (GR). These findings were corroborated with a promoter construct that contained 1.9 kilobases of 5 '-up-stream rat GFAP DNA with a luciferase reporter. Thus, the direction of GFAP transcription to CORT is subject to the postreplicative time in culture and to interactions with neurons, in which 5 -up-stream sequences contain sufficient information to mediate the switch in the direction of the response to CORT. This in vitro model may be used to analyze how interactions of astrocytes with neurons or other cell types influence the hormonal regulation of GFAP. (Endocrinology 136: 2066-2073, 1995)
$\mathrm{G}^{\mathrm{L}}$ IAL FIBRILLARY acidic protein (GFAP) is an intermediate filament protein of astrocytes that has importance to neuroendocrine mechanisms for two major reasons: 1$)$ its levels are regulated by a wide range of hormones, e.g. glucocorticoids (1-5), sex steroids (6-8), and cytokines (1, 9); and 2) the amount of GFAP can modulate interactions of astrocytes with neurons. In the rat hypothalamus on proestrus, GFAP-containing astrocytic processes expand, apparently displacing $\gamma$-aminobutyric acid-ergic afferents before the preovulatory gonadotropin surge (7); GFAP messenger RNA (mRNA) also increases during proestrus (8). More direct evidence for the role of GFAP in astrocyte-neuron interactions is that antisense GFAP mRNA blocked the induction of astrocytic processes in response to neurons during coculture (10).

GFAP mRNA is modulated at several levels of control (1). As determined by nuclear run-on assays, glucocorticoids decrease GFAP mRNA and transcription in the hippocampus and cerebral cortex $(2,5)$, whereas tumor necrosis factor lowers GFAP mRNA in cultured astrocytes without altering

Received November 16, 1994.

Address all correspondence and requests for reprints to: Dr. Irina Rozovsky, University of Southern California, Andrus Gerontology Center, 3715 McClintock Avenue, Los Angeles, California 90089-0191.

* This work was supported by USPHS Grants AG-7909 (to C.E.F.), from the John D. and Katherine T. MacArthur Foundation Network in Successful Aging, and National Research Scientist Award AG-05593 (to I.R.). its transcription (9). The transcriptional regulation of GFAP by glucocorticoids may be complex and indirect, because its response is several hours slower than that of glutamine synthetase (GS), a gene that is rapidly induced by glucocorticoids in astrocytes (5). Astrocytes possess two receptor types that mediate responses to corticosteroids, type I [mineralocorticoid (MR)] and type II [glucocorticoid (GR)] (11). GRs bind to canonical glucocorticoid response elements (GRE) (12) that mediate transcriptional control. The rat GFAP 5'up-stream promoter has several putative GREs (1), at least one of which is functional (13). Type II receptors mediate the control of GFAP by corticosterone (CORT) (2). Other transcriptional controls of GFAP regulate responses to CAMP (14) and phorbol esters [the TPA (tetradecanoyl-phorbol ester) response element, known to bind activating protein-1 (AP-1)] (15) and during development (16). DNA methylation of the up-stream promoter and coding sequences also varies quantitatively between brain regions and cell types and may influence transcription (17). The GFAP promoter contains clusters of putative response elements for diverse hormones and inflammatory mediators that imply multiaxis neuroendocrine controls over transcription (1).

The regulation of GFAP by glucocorticoids is subject to local factors in the brain. For example, there is an asymmetry in the inhibition of GFAP expression by CORT, such that elevations of GFAP mRNA in the hippocampus that result from deafferenting lesions are inhibited by CORT on the contralateral side, but not ipsilateral to the lesion (18). 

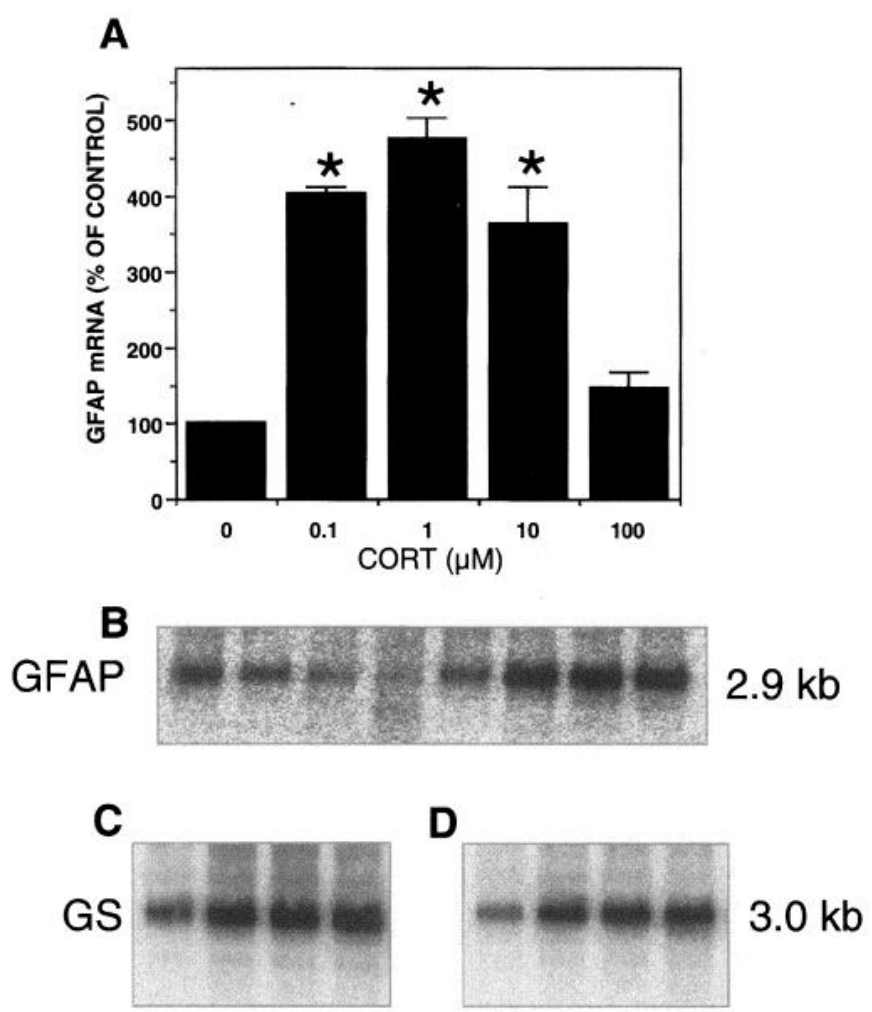

FIG. 1. Effect of CORT on GFAP and GS mRNAs in cultured astrocytes. A, GFAP mRNA $6 \mathrm{~h}$ after CORT treatment of short term primary neonatal cortical astrocytes in serum-free medium in vitro. Total cellular RNA was analyzed with GFAP cRNA probe by Northern blot hybridization. Integrated optical densities of autoradiographs were expressed as a percentage of the untreated control value (mean \pm SEM of three independent experiments). ${ }^{*}, P<$ 0.03 . B, Northern blots with total cellular RNA ( $3 \mu \mathrm{g} /$ lane), showing GFAP mRNA signals $(2.9 \mathrm{~kb})$ in control and CORT-treated $(1 \mu \mathrm{M}$; $6 \mathrm{~h}$ ) short and long term astrocyte cultures. Lanes (left to right) 1-4, Long term; lanes 1 and 2, controls; lanes 3 and 4, CORT; lanes 5-8, short term; lane 5, control; lanes 6-8, CORT. C and D, Northern blots with total cellular RNA ( $3 \mu \mathrm{g} /$ lane), showing GS mRNA $(3.0 \mathrm{~kb})$ in long and short term astrocyte cultures, respectively. Lane 1, Controls; lanes 2-4, CORT (1 $\mu \mathrm{M} ; 6 \mathrm{~h})$.

Local factors that differentially regulate GFAP between the lesioned and nonlesioned sides could include altered neuron-astrocyte interactions during the degeneration of neuron terminals and astrocyte proliferation. Both local and systemic factors may be important in the changes in GFAP expression during ovulation $(7,8)$ and parturition $(19)$ and in response to altered neuron electrical activity (20).

We are developing in vitro models for analyzing hormonal mechanisms in these complex features of GFAP regulation. In contrast to in vivo responses, CORT increased GFAP in primary cultures of astrocytes and in C6 gliomas $(13,21)$. This investigation focuses on determinants of the direction of GFAP transcription in response to CORT, a phenotype that shows extensive plasticity. We also examined two other astrocyte mRNAs: GS, which, in contrast to GFAP, is induced in response to CORT; and vimentin (VIM), another intermediate filament protein that does not show transcriptional regulation by CORT in vivo (5). Because GFAP immunoreactivity is reduced by coculture with neurons $(22,23)$, we also examined responses to CORT in astrocyte-neuron cocultures.

\section{Materials and Methods}

\section{Primary brain cell cultures}

Primary neonatal astrocytes were originated from the cerebral cortex of 1- to 3-day-old F344 rat pups after mechanical dissociation (24). Cells were plated in plastic culture dishes at $2 \times 10^{5} \mathrm{cell} / \mathrm{cm}^{2}$ and maintained in Dulbecco's Modified Eagle's Medium-Ham's F-12 Culture Medium (Cellgro) supplemented with $10 \%$ fetal bovine serum (Gibco, Grand Island, NY), $100 \mathrm{U} / \mathrm{ml}$ penicillin, and $50 \mathrm{U} / \mathrm{ml}$ streptomycin (Sigma Chemical Co., St. Louis, $\mathrm{MO}$ ) at $37 \mathrm{C}$ in a $5 \% \mathrm{CO}_{2}-95 \%$ air incubator, with medium renewal every $2-3$ days until confluence (10-12 days). Confluent cultures were purified from contaminating microglia and oligodendrocytes by shaking (25). Twenty-four hours before CORT treatment, culture medium was changed to serum-free medium. CORT was dissolved in $80 \%$ ethanol; equivalent ethanol was added to control cultures. Six or $24 \mathrm{~h}$ after CORT treatment in serum-free medium, cells were harvested for RNA isolation, protein studies, or nuclear run-on transcription assay. Primary neurons were derived from the cerebral cortex of 18-day-old embryos. After mechanical dissociation, 5 million cells were plated on the bed layer of confluent astrocytes ( 15 million cells/flask) and maintained in mixed sandwich cocultures for 8 days in serum-free chemically defined medium (26).

\section{RNA isolation and blot hybridization}

Total cellular RNA was isolated by a guanidinium thiocyanate-phenol-chloroform procedure (27). RNA gel blots were hybridized with $\left[{ }^{32} \mathrm{P}\right]$ complementary (c) RNA probes for GFAP and GS, which were transcribed from cDNA subclones in Bluescript $\mathrm{SK}^{+}$(Stratagene, $\mathrm{La}$ Jolla, CA): rat GFAP [2.7 kilobases (kb), including coding and $3^{\prime}$-untranslated region (UTR)] and rat GS (1.6 kb of mostly $3^{\prime}$-UTR) $(2,28)$. Integrated optical densities of autoradiographs were measured via computerized video densitometry.

\section{Nuclear run-on assay}

Transcription rates were estimated by run-on assay in control and CORT-treated cultured astrocytes $\left(30 \times 10^{6}\right.$ cells) (5). Transcripts labeled with [ ${ }^{32}$ P]UTP $\left(5-10 \times 10^{6} \mathrm{cpm}\right)$ were hybridized to slot blots made with $1 \mu \mathrm{g}$ cDNA that was alkali-linked to nylon membranes (Zeta-Probe, Bio-Rad Laboratories, Richmond, CA). Three nonoverlapping GFAP cDNA probes were used, covering exons 1-6 (cDNA), intron I $(0.9 \mathrm{~kb})$, and intron VIII $(0.6 \mathrm{~kb})$. GFAP intron probes were cloned into pCRII (Invitrogen, San Diego, CA) (5). GS and VIM transcription rates were studied using cDNA probes to 3 '-sequences. Blot signals were measured by phosphorimaging.

\section{GFAP promoter construct and transfection of primary astrocytes}

5 '-Up-stream sequences $1.9 \mathrm{~kb}$ of the rat GFAP promoter $(1,13)$ were cloned into pGL2 basic plasmid (Promega, Madison, WI). Short and long term primary astrocyte cultures were transfected with this construct using the transfection reagent DOTAP (Boehringer Mannheim, Indianapolis, IN). Luciferase activity was measured in cell lysates by the luciferase assay system (Promega). The activity was normalized to total protein (Coomassie protein assay, Pierce Chemical Co., Rockford, IL). For standardization of transfection efficiencies, $\beta$-galactosidase activity was measured in cell lysates after cotransfection with the pSV- $\beta$-galactosidase control vector (Promega). Data are expressed as a percentage of the vehicle-treated control value (mean \pm SEM).

\section{In situ hybridization}

Cells (monotypic astrocyte and astrocyte-neuron cocultures) were plated on poly-L-lysine-coated slides, treated with CORT $(1 \mu \mathrm{M})$ for $6 \mathrm{~h}$, 
TABLE 1. GFAP mRNA and protein after CORT treatment of primary neonatal astrocytes in vitro

\begin{tabular}{lcccc}
\hline & \multicolumn{2}{c}{ Long term (3 months) } & \multicolumn{2}{c}{$\begin{array}{c}\text { Short term (3 weeks) } \\
\text { mRNA }\end{array}$} \\
\cline { 2 - 5 } & $\begin{array}{c}\text { mRNA } \\
(\% \text { of Control) }\end{array}$ & $\begin{array}{c}\text { Protein } \\
(\mu \mathrm{g} / \mathrm{mg})\end{array}$ & $\begin{array}{c}\text { Protein } \\
(\mu \mathrm{g} / \mathrm{mg})\end{array}$ \\
\hline Control control) & $100.00 \pm 1.23$ & $2.09 \pm 0.176$ \\
CORT $(1 \mu \mathrm{M}$ & $100.0 \pm 2.3$ & $5.80 \pm 0.16$ & $472.00 \pm 21.50^{a}$ & $2.90 \pm 0.180^{b}$ \\
\hline
\end{tabular}

Total RNA from cultured astrocytes treated with CORT for 6 h was analyzed with rat GFAP cRNA probe by Northern blot hybridization. Integrated optical densities of autoradiographs were expressed as a percentage of the of untreated control value. Values are the mean \pm SEM of four independent experiments. GFAP protein was measured in cell-free homogenates by sandwich ELISA $24 \mathrm{~h}$ after CORT treatment. Data are expressed as micrograms of GFAP per mg total protein (mean \pm SEM of three independent experiments). Data for GFAP mRNA in short term cultures are also displayed in Fig. 1.

${ }^{a} P<0.03$

${ }^{\circ} P<0.05$.

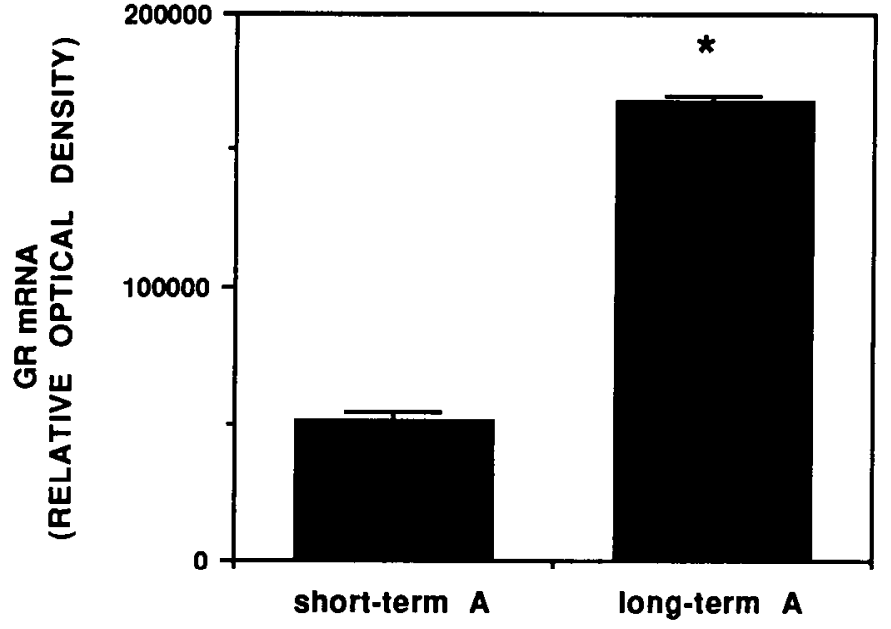

FiG. 2. GR mRNA prevalence increased in long term astrocyte cultures compared with that in short term astrocyte cultures. Data represent integrated optical densities of Northern blot autoradiographs of the major $7.0-\mathrm{kb}$ band of GR mRNA (mean \pm SEM of three independent experiments). ${ }^{*}, P<0.03$.

fixed in $4 \%$ paraformaldehyde for $24 \mathrm{~h}$, dehydrated in ethanol, and air dried. Fixed cells were rinsed in $0.1 \mathrm{M}$ triethanolamine, $\mathrm{pH} 8.0$, and incubated in acetic anhydride $(0.25 \%)$-triethanolamine for $10 \mathrm{~min}$. Before hybridization, cells were treated with proteinase- $\mathrm{K}(1 \mu \mathrm{g} / \mathrm{ml} ; 15 \mathrm{~min} ; 37$ C) in $0.1 \mathrm{M}$ Tris ( $\mathrm{pH} \mathrm{8.0)}$ and $50 \mathrm{~mm}$ EDTA, followed by treatment with $50 \mathrm{mM} \mathrm{HCl}(10 \mathrm{~min} ; 25 \mathrm{C})$. Hybridization with [ ${ }^{35} \mathrm{~S}$ ]GFAP cRNA $(0.3$ $\mu \mathrm{g} / \mathrm{ml} \cdot \mathrm{kb}$ probe) was performed for $3 \mathrm{~h}$ at $55 \mathrm{C}$; sense strand $\mathrm{cRNA}$ served as a control $(6,8)$. After ribonuclease treatment at $37 \mathrm{C}(25 \mu \mathrm{g} / \mathrm{ml}$ ribonuclease- $A)$ and a high stringency wash $(50 \%$ formamide and $0.5 \mathrm{M}$ $\mathrm{NaCl}$ at $63 \mathrm{C}$ ), slides were dehydrated and dipped in emulsion (Kodak NTB-2, Eastman Kodak, Rochester, NY). Crain density was estimated by video imaging.

\section{GFAP protein by enzyme-linked immunosorbent assay (ELISA) and immunocytochemistry}

GFAP in cell-free homogenates was assayed by sandwich ELISA with minor modifications (29). Plates were coated with polyclonal anti-GFAP for $1 \mathrm{~h}$; dilutions of samples and BSA standards were prepared robotically. For immunocytochemistry, mixed astrocyte-neuron cocultures were fixed in $4 \%$ paraformaldehyde for $30 \mathrm{~min}$, rinsed in PBS [137 $\mathrm{mm}$ $\mathrm{NaCl}, 2.7 \mathrm{~mm} \mathrm{KCl}, 4.3 \mathrm{~mm}$ sodium phosphate (dibasic), and $1.4 \mathrm{~mm}$ potassium phosphate (monobasic)], treated with $1 \%$ Nonidet P-40 for 20 min and normal serum for $30 \mathrm{~min}$, and incubated overnight with primary antibodies: monoclonal anti-GFAP (concentration, $2.5 \mu \mathrm{g} / \mathrm{ml}$; 1:500 dilution) and rabbit polyclonal antineurofilament (1:500 dilution; Boehringer Mannheim). Secondary antibodies (antimouse fluorescein isothiocyanate conjugated and antirabbit rhodamine conjugated; 1:50 dilution; Boehringer Mannheim) were applied for $1 \mathrm{~h}$.

\section{Statistical analysis}

One-way analysis of variance ( $F$ test; Statview, Abacus Concepts, Berkeley, CA) was used for statistical analysis of data.

\section{Results}

GFAP expression is induced by COR' in short term (21-day) astrocyte cultures

Primary astrocytes from neonatal rats were cultured for 21 days and were at confluence for about the last 7 days. This duration of culture was chosen because levels of type II GR receptors are higher at 21 days than at 10 days (11). Six hours after the introduction of CORT at a range of physiological concentrations in serum-free medium, we observed a biphasic dose response, with the greatest increase in GF $\Lambda$ P $m R N \Lambda$ (4.7-fold) at $1 \mu \mathrm{M}$ CORT (Fig. 1A and Table 1). GFAP protein also increased $24 \mathrm{~h}$ after CORT treatment $(1 \mu \mathrm{M})$ (Table 1 ). Astrocyte morphology was not altered at 6-24 h (not shown).

\section{GFAP expression is inhibited by CORT in long term (3-} month) astrocyte cultures

To evaluate time-dependent influences that may reflect differential expression of the GR (11), we examined astrocyte cultures that were confluent for 3 months instead of 7 days. Medium was replaced every 3 days without replating to maintain confluence. In contrast to short term cultures, in these long term cultures, CORT caused a decrease in GFAP mRNA and protein (Table 1 and Fig. 1B). This direction of GFAP response to CORT models in vivo responses (see introduction). Long term astrocyte cultures had a 3-fold higher prevalence of GR mRNA than short term cultures (Fig. 2).

The switch in the direction of GFAP regulation by CORT from positive to negative occurred between 2-3 months in culture (not shown). Secondary cultures derived from primary long term cultures retained their ability to proliferate and reached confluence by 3 weeks after second passage. These astrocytes also retained the CORT-mediated decrease in GFAP mRNA (not shown), as observed in the long term cultures of parental cells. In contrast, secondary cultures derived from primary neonatal astrocytes were cultured for 21 days and retained the induction of GFAP mRNA and protein by CORT (not shown). 
A

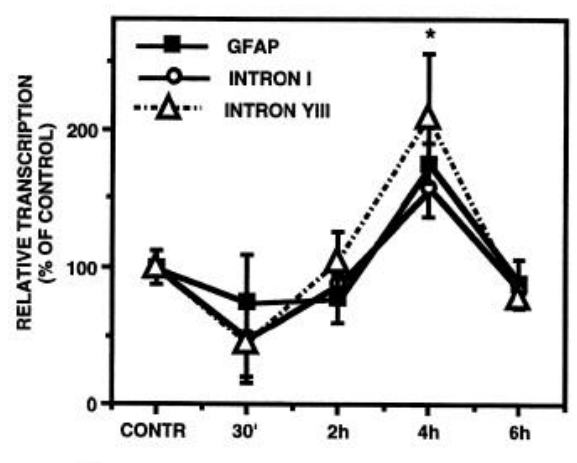

C

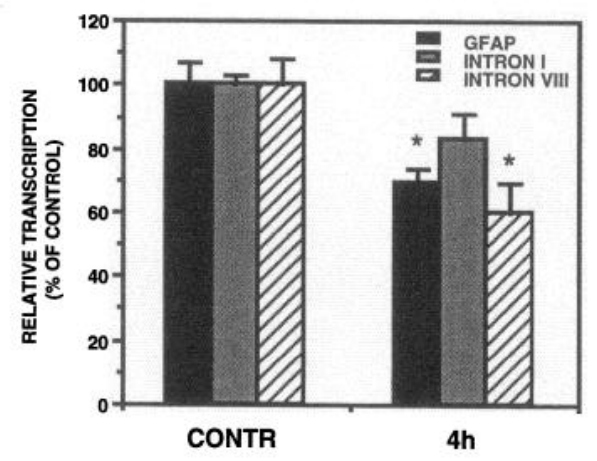

B

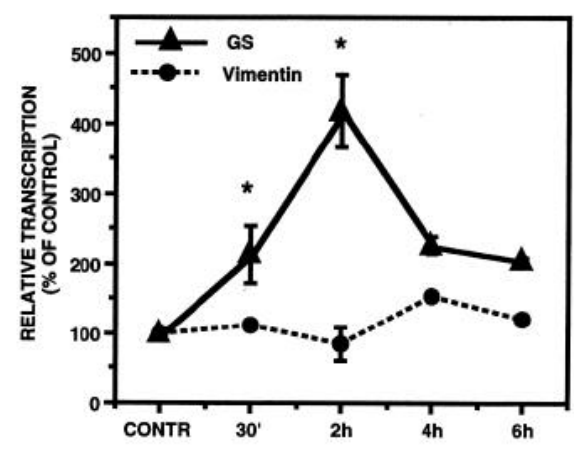

D

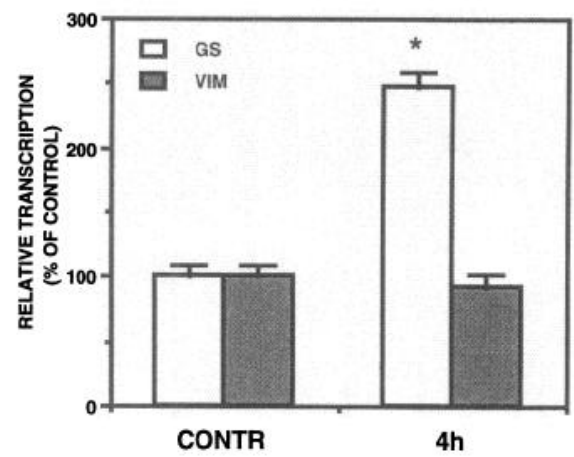

TABLE 2. Regulation of GFAP transcription in long and short term astrocyte cultures by CORT

\begin{tabular}{|c|c|c|c|c|}
\hline & \multicolumn{2}{|c|}{$\begin{array}{l}\text { Activity of endogenous GFAP promoter } \\
\text { (transcription rates by run-on assay using } \\
\text { GFAP cDNA probe, } \% \text { of control) }\end{array}$} & \multicolumn{2}{|c|}{$\begin{array}{l}\text { Activity of exogenous GFAP promoter (after } \\
\text { transfection of } 1.9 \mathrm{~kb} \text { GFAP promoter with } \\
\text { luciferase reporter, } \% \text { of control) }\end{array}$} \\
\hline & Long term & Short term & Long term & Short term \\
\hline Control & $100 \pm 7$ & $100 \pm 12$ & $100 \pm 9$ & $100 \pm 13$ \\
\hline CORT $(1 \mu \mathrm{M})$ & $69 \pm 5^{a}$ & $176 \pm 15^{\alpha}$ & $60 \pm 10^{a}$ & $190 \pm 18^{a}$ \\
\hline
\end{tabular}

GFAP transcription was analyzed by both nuclear run-on assay and with a promoter construct that contained $1.9 \mathrm{~kb}$ of 5 '-up-stream rat GFAP DNA with a luciferase reporter after CORT treatment of long and short term astrocytes in vitro. Relative transcription rates by nuclear run-on assay were analyzed by phosphor imaging and expressed as a percentage of the untreated control value (mean \pm SEM of four independent experiments). Luciferase activity measured in lysates of transfected cells was normalized to total protein and $\beta$-galactosidase. $\beta$-Galactosidase activity was measured for standardization of transfection efficiency after cotransfection of GFAP construct with pSV- $\beta$-galactosidase control vector. Data are expressed as a percentage of the untreated control value (mean \pm SEM of three independent experiments).

${ }^{a} P<0.05$.

\section{GS induction by CORT is not influenced by culture duration}

For comparison with GFAP, we also examined GS, another astrocyte gene whose transcription was rapidly induced by glucocorticoids in vivo (5). GS mRNA was induced by CORT $(1 \mu \mathrm{M})$ in both long and short term astrocyte cultures (Fig. 1, $\mathrm{C}$ and D) as well as in secondary cultures of both origins (not shown). Therefore, there is no switch in the direction of GS regulation by CORT in astrocytes in vitro.

\section{Transcriptional regulation of GFAP, GS, and VIM by CORT}

Because GFAP mRNA levels can be regulated independently of transcription (see introduction), it was necessary to show that these responses to CORT were mediated transcriptionally, which was achieved by run-on assay and by a promoter construct. In short term astrocyte cultures, CORT $(1 \mu \mathrm{M})$ increased GFAP transcription rates to a maximum by about $4 \mathrm{~h}$ (Fig. 3A and Table 2). In contrast, CORT caused a faster increase in GS transcription; increases were detected by $30 \mathrm{~min}$ and reached a maximum at $2 \mathrm{~h}$ (Fig. 3B). VIM transcription was not influenced by CORT (Fig. 3B), as observed in vivo (5).

In long term astrocyte cultures, CORT $(1 \mu \mathrm{M})$ caused a decrease in GFAP transcription rates (Fig. 4C and Table 2), in agreement with the direction of response of GFAP mRNA. CORT also increased the GS transcription rate, but did not change VIM transcription (Fig. 3D), as observed in vivo (5).

To further establish the effects of CORT on GFAP transcription, we used a construct that contained the 1.9-kb 5'up-stream flanking region of rat GFAP gene with luciferase reporter. These promoter sequences contain at least one functional GRE, as evaluated by transfection into C6 glioma cells 

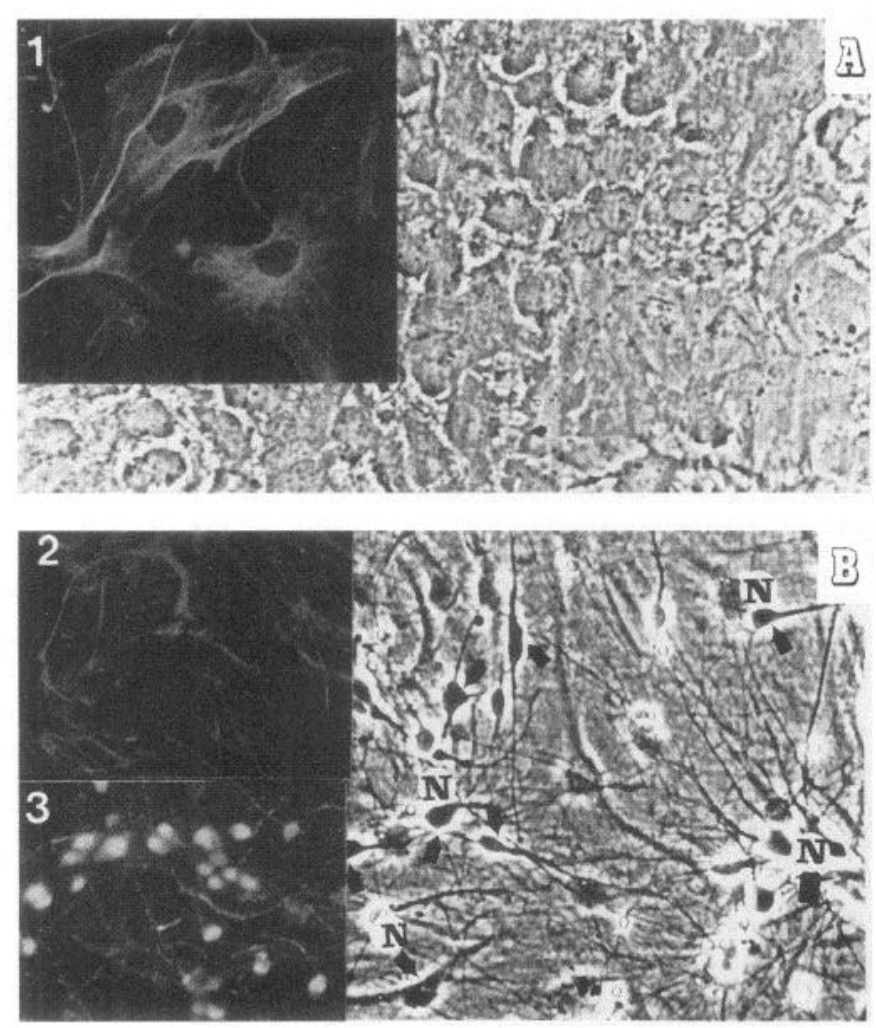

Fig. 4. Double immunolabeling of mixed neuron-astrocyte cocultures. A, Monotypic primary neonatal astrocytes at confluence. 1, GFAP immunostaining in this culture (fluorescein isothiocyanateconjugated secondary antibody). B, Coculture of neurons and astrocytes; neurons $(\mathrm{N})$ are marked with arrows. 2, GFAP-immunopositive astrocytes in double immunostained coculture; 3 , neurofilament-positive neurons (rhodamine-conjugated secondary antibody). Magnification, $\times 312.5 ;$ bar $=10 \mu \mathrm{m}$.

(13). CORT treatment of short term astrocyte cultures transfected with this GFAP promoter construct showed a $190 \pm$ $18 \%$ increase in GFAP promoter activity. However, long term cultured astrocytes with the same full-length GFAP promoter construct showed a $60 \pm 10 \%$ decrease in GFAP promoter activity after $4 \mathrm{~h}$ of CORT treatment (see Table 2). Transfection efficiencies were identical in short and long term astrocytes when monitored by $\beta$-galactosidase activity after cotransfection of GFAP-luciferase vector with pSV- $\beta$ galactosidase control vector (not shown).

\section{GFAP mRNA expression in astrocyte-neuron cocultures}

Astrocyte interactions with neurons modulate astrocyte morphology and GFAP expression (see introduction). Therefore, we examined short term cultures of primary neonatal cortical astrocytes and embryonic cortical neurons (3:1 ratio, astrocytes/neurons). Astrocytes, which are typically flat and polygonal, when grown in the presence of neurons extended GFAP-immunopositive processes (Fig. 4). By Northern blot hybridization, GFAP mRNA was decreased in these mixed neuron-glia cultures (Fig. 5A).

Six hours of CORT treatment further decreased GFAP mRNA in astrocyte-neuron cocultures (Fig. 5B). This direction of response models that observed in vivo and contrasts with responses of short term monotypic astrocyte cultures.
However, the presence of neurons did not affect the responses of GS to CORT (Fig. 5B).

To further resolve the cellular basis for the effects of coculture, we showed by in situ hybridization that GFAP mRNA per astrocyte in astrocyte-neuron cocultures was $50 \%$ lower than that in monotypic astrocyte cultures (Fig. 5C). Six hours of CORT treatment caused a 3-fold increase in GFAP mRNA content per astrocyte in monotypic astrocyte cultures, but caused a 2-fold decrease in GFAP mRNA per astrocyte in astrocyte-neuron cocultures (Fig. 5C).

Because the direction of response of the chromatin structure of nonneural cells to glucocorticoids can be influenced by factors in the conditioned medium (30), we examined the medium. The culture medium conditioned by primary neurons or by cocultures of astrocytes and neurons did not affect the direction of GFAP regulation by CORT in neonatal astrocyte cultures (not shown).

\section{Discussion}

These studies on cultured primary astrocytes revealed features in the regulation of GFAP by CORT that give insight into the neuroendocrine involvement of GFAP in vivo. We first discuss how the duration of culture influences responses and then the effects of coculture with neurons.

In short term (21-day) primary cultures of astrocytes from neonatal rats, CORT induced GFAP transcription, mRNA, and protein. This direction of response is opposite the CORTmediated decrease in GFAP mRNA and protein observed in vivo in adult rats. Because CORT decreases GFAP mRNA in neonatal rats (4) as in adults, we conclude that the direction of response to CORT does not depend on the schedule of differentiation. In neonatal rats, GFAP expression is far below adult levels, but increases rapidly (reviewed in Refs. 1 and 16).

The transcriptional level of response to CORT by primary astrocytes was shown by run-on assays and by responses of a transfected rat GFAP promoter construct containing $1.9 \mathrm{~kb}$ of 5'-up-stream sequence. By run-on assay, the increased transcription of GFAP in short term astrocyte cultures was detected after a delay of $4 \mathrm{~h}$, as observed in vivo (5). In contrast to GFAP, CORT treatment of the same cultured cells caused a rapid increase in GS transcription at $30 \mathrm{~min}$. Thus, the characteristic slowness of GFAP transcriptional responses to CORT is maintained in short term cultures, although the direction of response is opposite that in vivo. The delayed increase in GFAP induction by CORT suggests that the induction is mediated by an indirect mechanism secondary to activation of type II glucocorticoid receptors. The data also indicate posttranscriptional regulation, because induction by CORT is greater for GFAP mRNA than GFAP protein. GFAP protein has heterogeneous turnover rates that favor multiple levels of regulation; a shorter-lived pool of GFAP has a halflife of $18 \mathrm{~h}$ or less $(31,32)$.

The duration of time at confluence influenced the direction of response of GFAP expression to CORT. In long term (3month) primary astrocyte cultures that were confluent for more than 2 months, CORT treatment repressed GFAP transcription and GFAP mRNA and protein, as observed in vivo 


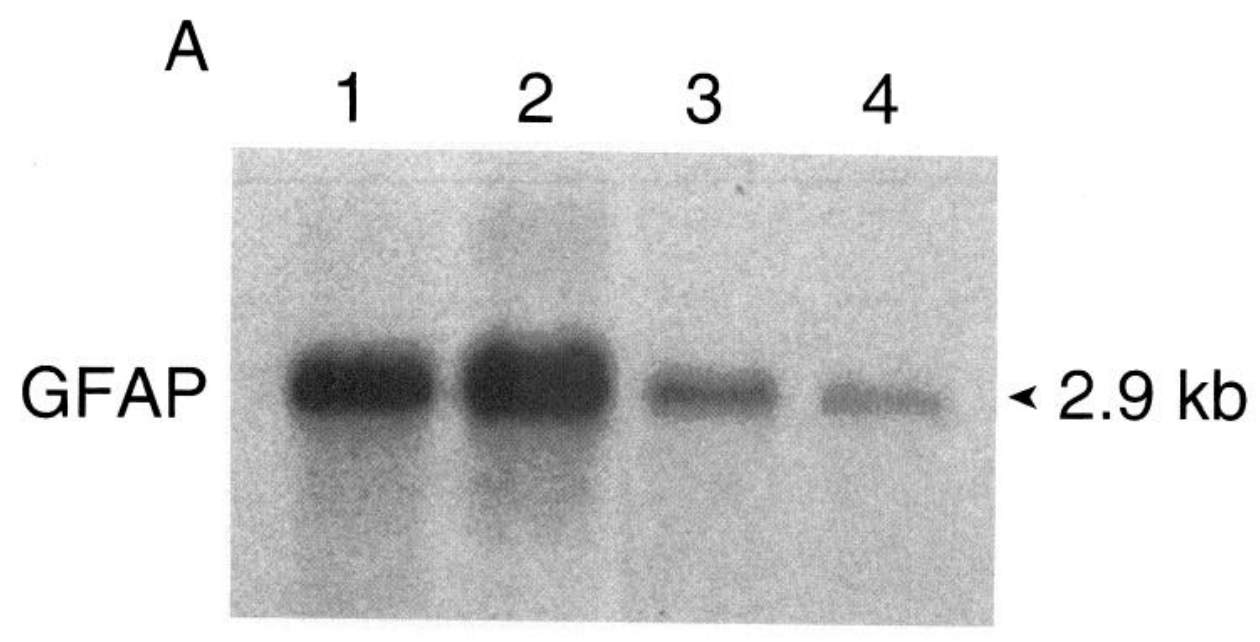

FIG. 5. Effects of CORT on GFAP and GS mRNAs in mixed primary neuronastrocyte cocultures. Fetal cortical neurons ( 5 million cells) were plated on the formed monolayer of neonatal cortical astrocytes $(\sim 12$ million cells total), cocultured for 8 days in serum-free chemically defined medium, and then treated with CORT $(1 \mu \mathrm{M})$ for $6 \mathrm{~h}$. A, Northern blot hybridization analysis. Total cellular RNA ( $5 \mu \mathrm{g} /$ lane) was analyzed with GFAP cRNA probe. Lanes 1-2, Monotypic astrocyte culture; lane 1 , control; lane 2, CORT; lanes 3 and 4 , astrocyte-neuron cocultures; lane 3, control; lane 4, CORT. B, CORT-mediated changes in GFAP and GS mRNA in astrocyte-neuron cocultures. Integrated optical densities were expressed as a percentage of the untreated control value. C, In situ hybridization analysis of GFAP mRNA in mixed astrocyte-neuron cocultures $6 \mathrm{~h}$ after CORT treatment. Data are expressed as the average number of grains per single astrocyte. Seventy to 100 cells were analyzed in each experimental group. Values are the mean \pm SEM of four independent experiments. ${ }^{*}, P<0.05$.
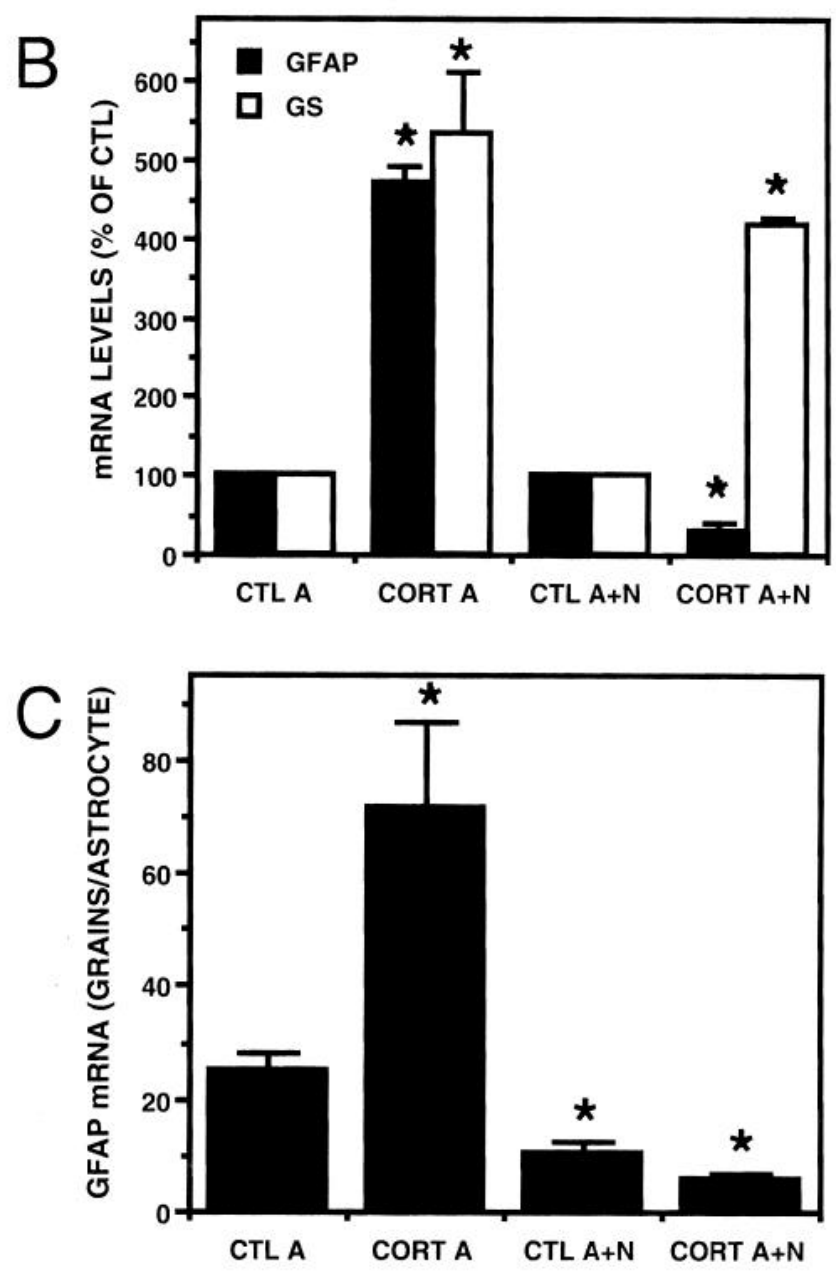

(5). As observed in the short term culture and in vivo, CORT induced GS transcription. Subculturing of primary astrocytes from either short or long term cultures did not alter their positive or negative (respectively) responses to CORT, when observed at a second confluence 21 days later. Thus, the directional phenotype of GFAP responses to CORT persists through subsequent replication.

These phenomena differ from the cell culture aging or proliferative cellular senescence observed in primary fibroblast cultures, in which replication is lost during serial culture, in association with major changes in the expression of growth regulatory genes (33). In these studies, long term cultures are readily stimulated to resume proliferation upon replating; presumably, proliferative limits would be demonstrated if extended to multiple serial subcultures. Other studies of astrocytes in long term primary cultures 
( 2 months) show a stable quiescent state in G1 that is subject to cell density inhibition and from which cells can be stimulated by isoprenoids to reenter the mitotic cycle (34).

The long term cultures resemble long quiescent brain astroglia that can be stimulated to proliferate in response to injury and neurodegeneration (35). Postreplicative time in culture could alter the direction of astrocytic responses to CORT and other hormones that vary during the course of Alzheimer's and other diseases associated with increased numbers of hyperactive astrocytes. Astrocyte proliferation is stimulated by other hormones, e.g. PRL (36), and inflammatory mediators, e.g. $\gamma$-interferon (37). Thus, the timing of astrocyte proliferation could influence the outcomes in GFAP expression in response to changes in CORT and other hormones that may be altered during chronic diseases at any age.

Changes in receptors could be a mechanism in the altered responses of GFAP to CORT as a function of culture conditions, in view of the 3-fold increase in GR mRNA prevalence in long term vs. short term cultures. Differential expression of MRs and GRs in cultured astrocytes as a function of time in culture were also shown by ligand binding assays. The concentration of type I (MR) receptors in astrocytes cultured for 30 days was nearly half that in 20-day cultures (11), whereas the number of type II GR receptors in 20- and 30-day cultures was more than twice that in 10-day cultures. Because the decrease in GFAP mRNA and protein by CORT in vivo is mediated by type II receptors (2), the increase in type II receptors in astrocytes and/or the decrease in type I receptors with time in culture could mediate the switch in direction of the transcriptional response to CORT.

Heterotypic cell interactions also influence the direction of response to CORT. When mixed neuron-astrocyte cocultures were maintained for at least 8 days in vitro, CORT decreased the amount of GFAP mRNA per astrocyte. The GFAP mRNA content per astrocyte in these cocultures also decreased compared with that in monotypic cultured astrocytes, as briefly reported $(22,23)$. Of relevance to our results is the influence of astrocyte-neuron interactions on the transcription of type II receptors, which is increased in cocultures of avian retinal Müller glial cells by contact with neurons (38). We hypothesize that the switch in direction of the GFAP response to CORT is mediated by increased levels of GR in long term cultures and cocultures with neurons.

Other transcription factors are implicated besides the type II receptor in these interactions. Coculture of neurons with astrocytes can decrease levels of c-fos and JunD (23). "Wounding" of neurons in these mixed cocultures induced astrocytic GFAP, c-fos, and $J u n \mathrm{D}$ to levels found in monotypic astrocyte cultures (23). The proteins c-fos and c-jun form the AP-1-transcription factor complex, which can invert transcriptional responses to the glucocorticoid receptor from positive to negative. Another switch mechanism was found in the promoter of the proliferin gene, which contains a composite GRE that is bound by both the type II (GR) receptor and AP-1 transcription factors (39); the presence or absence of c-jun together with high levels of c-fos invert the transcriptional response to glucocorticoids. Whatever the relative importance of changes in type II receptors or AP-1 factors may prove to be for responses of GFAP to CORT, the first $1.9 \mathrm{~kb}$ of its $5^{\prime}$-up-stream promoter contain sufficient information to mediate the switch.

These findings are pertinent to brain region differences in the responses of GFAP to sex steroids. In contrast to the responses of GFAP to adrenalectomy or CORT, which showed no regionality $(1,2,5)$, orchidectomy increased GFAP mRNA in the hippocampus and cerebral cortex, but decreased GFAP mRNA in the hypothalamus (6). This direction of response to sex steroids is consistent with the increases in GFAP mRNA in the arcuate nucleus of the hypothalamus of female mice seen at proestrus, in association with elevations of estradiol (8). In view of the present findings, local activities of neurons could indirectly alter the regulation of GFAP during changes in sex steroid levels. The in vitro model described here could be used to analyze an emergent feature in neuroendocrine mechanisms: how local interactions of astrocytes with neurons or other cell types (40, 41 ) influence the regulation of GFAP and other astrocytic activities by hormones in the hypothalamus and limbic system.

\section{Acknowledgments}

We thank T. H. Hogan for help in maintaining cell cultures and assistance with photography. We also thank Ms. L. R. Bishop for expert assistance with the ELISA.

\section{References}

1. Laping NJ, Teter B, Nichols NR, Rozovsky I, Finch CE 1994 Glial fibrillary acidic protein: regulation by hormones, cytokines, and growth factors. Brain Pathol 4:259-275

2. Nichols NR, Osterburg HH, Masters JN, Millar SL, Finch CE 1990 Messenger RNA for glial fibrillary acidic protein is decreased in rat brain following acute and chronic corticosterone treatment. Mol Brain Res. 7:1-7

3. O'Callaghan JP, Brinton RE, McEwen BS 1989 Glucocorticoids regulate the concentration of glial fibrillary acidic protein throughout the brain. Brain Res 494:159-161

4. Tsuneshi S, Takade S, Motoike T, Ohashi T, Sano K, Nakamura H 1991 Effects of dexamethasone on the expression of myelin basic protein, proteolipid protein, and glial fibrillary acidic protein genes in developing rat brain. Dev Brain Res 61:117-123

5. Laping NJ, Nichols NR, Day, JR, Johnson SA, Finch CE 1994 Transcriptional control of glial fibrillary acidic protein and glutamine synthetase in vitro shows opposite responses to corticosterone in the hippocampus. Endocrinology 135:1928-1933

6. Day JR, Laping NJ, Lampert-Etchells M, Brown SA, O'Callaghan JP, McNeill TH, Finch CE 1993 Gonadal steroids regulate the expression of glial fibrillary acidic protein in the adult male rat hippocampus. Neuroscience 55:435-443

7. Garcia-Segura L, Luquin S, Parducz A, Naftolin F 1994 Gonadal hormone regulation of glial fibrillary acidic protein immunoreactivity and glial ultrastructure in the rat neuroendocrine hypothalamus. Glia 10:59-69

8. Kohama SG, Goss JR, McNeill TH, Finch CE 1995 GFAP mRNA increases at proestrus in the arcuate nucleus of mice. Neurosci Lett 183:164-166

9. Shafit-Zagardo B, Kume-Iwaki A, Goldman JE 1988 Astrocyte regulate GFAP mRNA levels by cyclic AMP and protein kinase C-dependent mechanisms. Glia 1:346-354

10. Weinstein DE, Shelanski ML, Liem RHK 1991 Suppression by antisense mRNA demonstrates a requirement for the glial fibrillary acidic protein in the formation of stable astrocytic processes in response to neurons. J Cell Biol. 112:1205-1213

11. Chou YC, Luttge WG, Sumners C 1991 Expression of mineralocor- 
ticoid type I and glucocorticoid type II receptors in astrocyte glia as a function of time in culture. Brain Res 16:55-61

12. Martinez E, Wahli W 1991 Characterization of hormone response elements. In: Parker MG (ed) Nuclear Hormone Receptors: Molecular Mechanisms, Cellular Functions, Clinical Abnormalities. Academic Press, New York, pp 125-153

13. Huang CI, Laping NJ, Rozovsky I, Hogan TH, Finch CE, Steroids differentially regulate the expression of the rat glial fibrillary acidic protein gene and ils promoter activily in C6 glioma. 75th Annual Meeting of The Endocrine Society, Las Vegas NV, 1993, p 208 (Abstract)

14. Kaneko R, Hagiwara N, Leader K, Sueoka N 1994 Glial-specific cAMP response of the glial fibrillary acidic protein gene in the RT4 lines. Proc Natl Acad Sci USA 91:4529-4533

15. Masood K, Besnard F, Su Y, Brenner M 1993 Analysis of a segment of the human glial fibrillary acidic protein gene that directs astrocyte-specific expression. J Neurochem 61:160-166

16. Brenner M 1994 Structure and transcriptional regulation of the GFAP gene. Brain Pathol 4:245-257

17. Teter B, Osterburg HH, Anderson C Finch CE 1994 Methylation of the rat glial fibrillary acidic protein gene shows tissue-specific domains. J Neurosci Res 39:680-693

18. Laping NJ, Nichols NR, Day JR, Finch CE 1991 Corticosterone differentially regulates the bilateral response of astrocyte mRNAs to entorhinal cortex lesions in male rats. Mol Brain Res 10:291-297

19. Hatton GI, Perlmutter LS, Salm AK, Tweedle CD 1984 Dynamic neuronal-glial interactions in hypothalamus and pituitary: implications for control of hormone synthesis and release. Peptides [Suppl 1] 5:121-138

20. Canady KS, Rubel EW 1992 Rapid and reversible astrocytic reaction to afferent activity blockade in chick cochlear nucleus. Neuroscience 13:769-779

21. Rozovsky I, Laping NJ, Hogan TH, Teter B, Nichols NR, Finch CE, Regulation of GFAP mRNA by glucocorticoids in vitro. 24th Annual Meeting of the Society for Neuroscience, Washington DC, 1993, p 43 (Abstract)

22. Penny packer KR, Hong JS, McMillian MK, Decrease in expression of GFAP and Jun transcription factors in neuron-glia co-cultures. 24th Annual Meeting of the Society for Neuroscience, Washington DC, 1993, p 447 (Abstract)

23. McMillian MK, Thai L, Wu G-S, Simmons KL, O'Callaghan JP, Hong JS, Pennypacker KR, Neuronal-glia co-cultures as model to study reactive gliosis. 24th Annual Meeting of the Society for Neuroscience, 1993, Washington DC, p 447 (Abstract)

24. McCarthy KD, de Vellis J 1980 Preparation of separate astroglial and oligodendroglial cell cultures from rat cerebral tissue. J Cell Biol 85:890-902

25. Giulian D, Baker TJ 1986 Characterization of ameboid microglia isolated from developing mammalian brain. J Neuroscience 6: 2163-2178

26. Brewer GJ, Cotman CW 1989 Survival and growth of hippocampal neurons in defined medium at low density: advantages of sandwich culture technique or low oxygen. Brain Res 494:65-74

27. Chomzynski P, Sacchi N 1987 Single-step method for RNA isolation by acid guanidinium thiocyanate-phenol-chloroform extraction. Anal Biochem 162:156-159

28. Nichols NR Masters JN, Finch CE 1994 Cloning of steroid-responsive mRNAs by differential hybridization. In: de Klot ER, Sutanto W (eds) Methods in Neuroscience. Academic Press 22:296-312

29. O'Callaghan JP 199I Quantification of glial fibrillary acidic protein: comparison of slot-immunobinding assays with novel sandwich ELISA. Neurotox Teratol 33:257-281

30. Johnson LK, Lan NC, Baxter J 1979 Stimulation and inhibition of cellular functions by glucocorticoids. J Biol Chem 254:7785-7794

31. Chiu FC, Goldman JE 1984 Synthesis and turnover of cytoskeletal proteins in cultured astrocytes. J Neurochem 42:166-174

32. Morrison RS, de Vellis J, Lee YL, Bradshaw RA, Eng LF 1985 Hormones and growth factors induce the synthesis of glial fibrillary acidic protein in rat brain astrocytes. J Neurosci Res 14:167-176

33. Campisi J 1992 Oncogenes, protooncogenes, and tumor suppressor genes: a hitchhiker's guide to senescence. Exp Gerontol 27:397-401

34. Langan TJ, Slater MC 1991 Quiescent astroglia in long-term cultures re-enter the cell cycle and require a non-sterol isoprenoid in late G1. Brain Res 548:9-17

35. Miller RH, Abney ER, David S, Ffrench-Constant C, Lindsay R, Patel R, Stone JM, Raff MC 1986 Is reactive gliosis a property of a distinct subpopulation of astrocytes? J Neurosci 6:22-29

36. DeVito WJ, Okulicz WC, Stone S, Avakian C 1992 Prolactin-stimulated mitogenesis of cultured astrocytes. Endocrinology 130: $2549-2556$

37. Yong VW, Moumdjian R, Yong FP, Ruijs TC, Freedman MS, Cashman N, Antel JP 1991 Gamma-Interferon promotes proliferation of adult human astrocytes in vitro and reactive gliosis in the adult mouse brain in vivo. Proc Natl Acad Sci USA 88:7016-7120

38. Reisfeld S, Vardimon L 1994 Cell to cell contacts control the transcriptional activity of the glucocorticoid receptor. Mol Endocrinol 8:1224-1233

39. Diamond MI, Miner JN, Yoshinaga SK, Yamamoto KR 1990 Transcription factor interactions: selectors of positive or negative regulation from single DNA element. Science 49:1266-1272

40. Vigé X, Tang B, Wise BC 1992 Cortical neurons inhibit basal and interleukin-1-stimulated astroglial cell secretion of nerve growth factor. Brain Res 591:345-350

41. Tontsch U, Rott O 1993 Cortical neurons selectively inhibit MHC class II induction in astrocytes but not in microglial cells. Int Immunol 5:249-254 